\title{
Original Article PARENTING STYLE AND ADOLESCENT ADJUSTMENT: FINDINGS OF A CROSS-SECTIONAL STUDY IN URBAN DHAKA
}

\author{
Armina Bhuiyan ${ }^{1}$, Md. Ziaul Islam ${ }^{2}$, Baizid Khoorshid Riaz ${ }^{3}$, Md. Hamdullah ${ }^{4}$
}

\begin{abstract}
Background: Adolescent adjustment is associated by parenting style as well as influenced by other factors of life. The objective of this study was to assess the association between parenting style and adolescent adjustment.
\end{abstract}

Methods: This cross-sectional study was conducted among 360 adolescents (180 boys and 180 girls) between 15-19 years selected by systematic random sampling from two institutions. Data were collected by semi-structured selfadministered questionnaire after taking informed written consent. The research was conducted in full accord with ethical principles and by keeping in view of the objectives of the study.

Results: Among the students, majority (74.2\%) were between 15-17 years. The mean ( \pm SD) of age was 16.66 $( \pm 1.108)$. Regarding parenting style, majority, $40.0 \%$ parents followed permissive style, $25.8 \%$ and $25.3 \%$ followed authoritative parenting. Only $8.9 \%$ followed negligent parenting. Majority, $59.7 \%$ of the adolescent were well adjusted. Parenting style was associated with adolescent adjustment $(\mathrm{p}<.01)$. There was significant mean difference in adjustment between boys and girls showing better adjustment of boys than girls $(\mathrm{p}<.01)$. Logistic regression between parenting style and adolescent adjustment showed, adjustment was high $(\mathrm{OR}=6.3)$ in permissive parenting.

Conclusion: This study showed there is significant influence of parenting style in adjustment of adolescent boys and girls which is related to the adjustment in almost all areas of life.

JOPSOM 2020; 39(2): 8-13

https://doi.org/10.3329/jopsom.v39i2.53160

Keywords: Parenting style, Adolescent, Adjustment

1. Dr. Armina Bhuiyan, Ex-student, MPH (Community Medicine) Program, NIPSOM, Mohakhali, Dhaka1212.

2. Professor Dr. Md. Ziaul Islam, PhD, Head, Department of Community Medicine, NIPSOM, Mohakhali, Dhaka-1212.

3. Professor Dr. Baizid Khoorshid Riaz, PhD, Head, Department of Public Health and Hospital Administration, NIPSOM, Mohakhali, Dhaka-1212

4. Dr. Md. Hamdullah, Medical Officer, Department of Community Medicine, NIPSOM, Mohakhali, Dhaka1212.

Correspondence: Prof. Dr. Md. Ziaul Islam,PhD, E-mail: dr.ziaul.islam@gmail.com

\section{INTRODUCTION}

Parents have huge impact on every person's life. A balanced relationship, mutual understanding and good interaction plays vital role for parents in their parenting and every adolescent for their adjustment. Parenting style can be defined, 'as the attitudes towards the child that are expressed through behaviors, gestures, tone of voice, or the spontaneous expression of emotion'. Developmental psychologist Diana Baumrind differentiated three parenting styles: authoritative, authoritarian, and permissive. It was published as Baumrind's Typology. ${ }^{1}$ Later, these were expanded by researchers and explained as four parenting styles, namely Authoritative, Authoritarian, Permissive and Neglectful/Uninvolved. ${ }^{2}$

The word 'adolescence' came from the Latin verb 'adolescere', which means 'to grow to maturity'. Adolescence period is the time when series of events undergo to grow in to adulthood. ${ }^{3}$ Adjustment has been considered as, "an index to integration; a harmonious behavior of the individual by which other individual of society recognize person is well adjusted". ${ }^{4}$ Satisfactory adjustments in adolescents are very important because of powerful influence on their developing personality. It helps in keeping balance between need and the capacity to meet needs. ${ }^{5}$ 
Parents- adolescent relationship is a complex. Conflicts arise because adolescents and parents differ in their expectations. ${ }^{6}$ In present circumstances there are many difficulties, for which typology of parenting styles has become most interesting field for research, as it is associated with developmental outcome of adolescents. Very few studies address the topic on adolescent adjustment with parenting styles in our country. Thus this study, will give us the recent picture of parenting style and its association with the adjustment of adolescent.

\section{METHODS}

The cross-sectional study was conducted among 360 adolescents of two institutions in Dhaka city; Dhaka Residential Model College, Mohammadpur and Azimpur Government Girls School and College, Azimpur from January to December 2018. Systematic random sampling technique was followed to include the participants. From both institutions 180 participants were included. Data was collected by a pre-tested semi- structured self-administered questionnaire based on Perceived Parenting Style Scale and The Adolescent Adjustment Scale. Informed written assent and consent was taken. The questionnaire was filled by the participants during regular school hours after taking written permission from the proper authorities of the respective institutions. Data were cleaned, edited and analyzed following the objectives and variables of the study using IBM software; Statistical Package for Social Sciences (SPSS). As inferential statistics, Chi-square test, t-test, One-way ANOVA, correlation and regression analysis were done to find significant associations.

\section{RESULTS}

Out of 360 participants, majority (74.2\%) were $15-17$ years old followed by (25.8\%) were in 18-19 years. The mean $\pm(\mathrm{SD})$ of the age was $16.66 \pm 1.108$. About $(50 \%)$ students were boy and $(50 \%)$ were girl. Around $(50 \%)$ were in secondary level followed by $(50 \%)$ were at higher secondary level. Majority of the students (95\%) were Muslim and (5\%) were Hindu. Majority, $(85.6 \%)$ came from nuclear family followed by $(14.4 \%)$ from joint family (Table-1). Among the fathers $(51.7 \%)$ were service holder followed by (48.3\%) were businessman. Average monthly family income was Tk.58727.97 \pm 33215.11 and $(56.7 \%)$ had Tk.20000-50000, (39.2\%) had Tk.51000-100000 and (4.2\%) had Tk.101000-200000 monthly family income (table 1).

Table 1. Socio-demographic characteristics of the students $(n=360)$

\begin{tabular}{|c|c|}
\hline Attributes & Findings \\
\hline Age & 15-17: $74.2 \%, 18-19: 25.8 \%$, Mean age: $16.66 \pm 1.10$ years \\
\hline Gender & Boy: $50.0 \%$, Girl: $50.0 \%$ \\
\hline Education & Secondary: $50.0 \%$, Higher secondary: $50.0 \%$ \\
\hline Religion & Islam: $95.0 \%$, Hindu: $5.0 \%$ \\
\hline Family type & Nuclear: $85.6 \%$, Joint: $14.4 \%$ \\
\hline Fathers' occupation & Service holder: $51.7 \%$, Businesses: $48.3 \%$ \\
\hline Monthly family income & 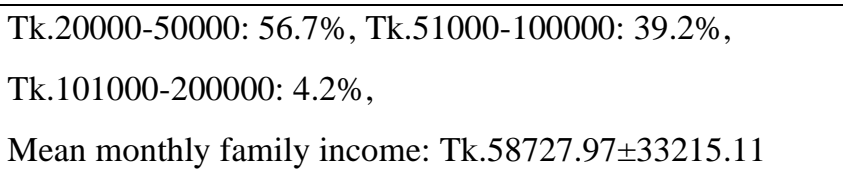 \\
\hline
\end{tabular}

Among parenting styles, majority, (40.0\%) parents followed permissive style followed by authoritative
(25.8\%), authoritarian (25.3\%) and (8.9\%) followed negligent parenting (Figure 1). 
Figure 1. Distribution of participants by different Parenting Styles

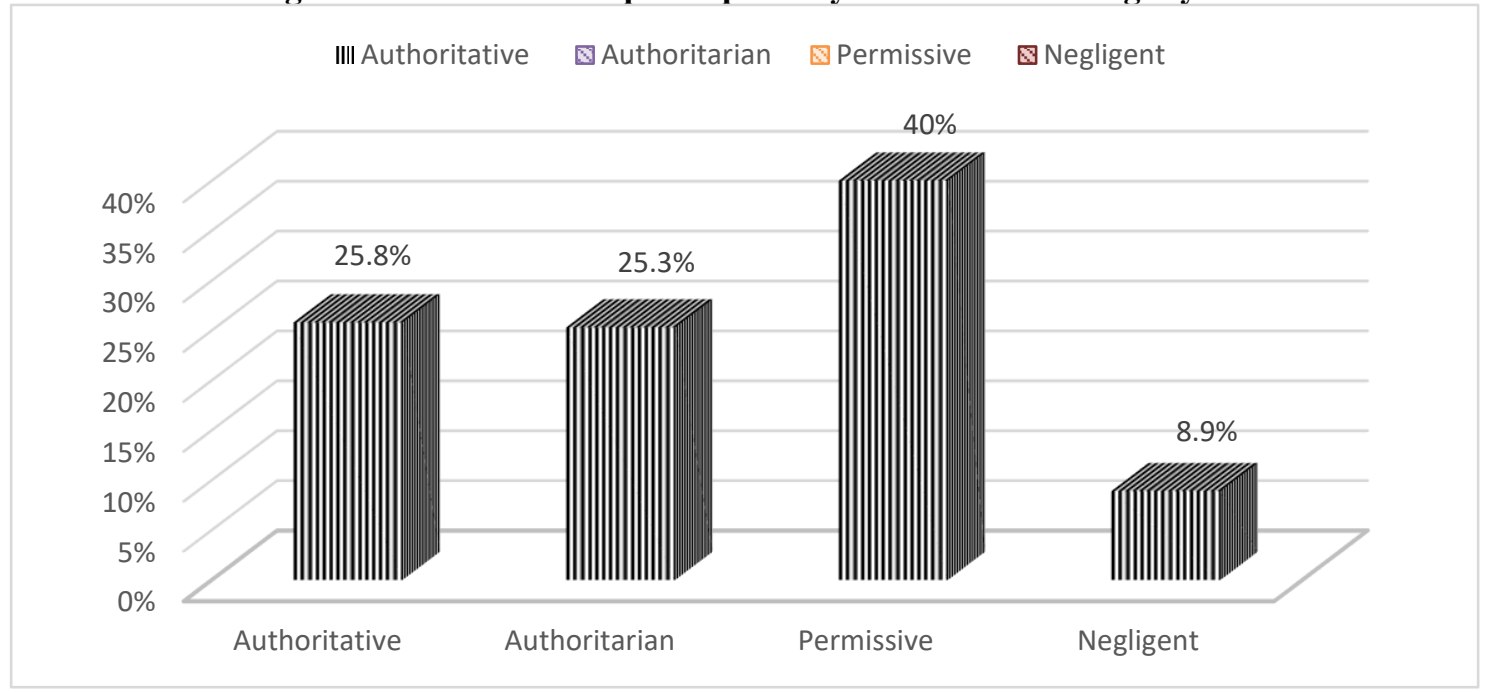

The study found participants by relationship with staffs, majority, (58.6\%) were not well-adjusted. By relationship with male peers and female Peers showed, $(63.3 \%)$ and $(70 \%)$ were well-adjusted. Responsibilities at school/work, majority, (64.7\%) were well-adjusted followed by $(35.3 \%)$ were not well-adjusted. At maintaining rules, $(72.8 \%)$ were well-adjusted and (27.2\%) were not well-adjusted.
Table-2 also showed, regarding self-attitude among students, majority, $(63.6 \%)$ were well-adjusted followed by $(36.4 \%)$ were not well-adjusted. In impulse control, majority, (55.0\%) were not welladjusted and $(45.0 \%)$ were well-adjusted. In realitytesting, Majority, $(60.8 \%)$ were well-adjusted and $(39.2 \%)$ were not well-adjusted (Table 2).

Table 2. Distribution of participants by ways adolescent adjustments (Based on Adolescent Adjustment Scale)

\begin{tabular}{|l|l|c|c|c|c|}
\hline \multicolumn{2}{|c|}{ Attributes } & \multicolumn{2}{c|}{ Well adjusted } & \multicolumn{2}{c|}{ Not well adjusted } \\
\cline { 3 - 6 } & Srequency & Percent & Frequency & Percent \\
\hline \multirow{3}{*}{ By relationship } & Staff & 149 & 41.4 & 211 & 58.6 \\
\cline { 2 - 6 } & Male peer & 228 & 63.3 & 132 & 36.7 \\
\cline { 2 - 6 } By responsibilities & Female peer & 252 & 70.0 & 108 & 30 \\
\hline \multirow{3}{*}{ Regarding self } & At school/work & 233 & 64.7 & 127 & 35.3 \\
\cline { 2 - 6 } & Maintaining rules & 262 & 72.8 & 98 & 27.2 \\
\cline { 2 - 6 } & Self-attitude & 229 & 63.6 & 131 & 36.4 \\
\cline { 2 - 6 } & Impulse control & 162 & 45.0 & 198 & 55.0 \\
\cline { 2 - 6 } & Reality testing & 219 & 60.8 & 141 & 39.2 \\
\hline
\end{tabular}

Association between different parenting styles and adolescent adjustment shows, $(74.3 \%)$ were well adjusted and $(25.7 \%)$ were not well adjusted who had permissive parents. About (69.9\%) were well adjusted and $(30.1 \%)$ were not well adjusted with authoritative parents. With authoritarian parents $(37.4 \%)$ and $(62.6 \%)$ were well adjusted and not well adjusted respectively. Those who had negligent parents, $(28.1 \%)$ were well adjusted and (71.9\%) were not well adjusted. The association between parenting style and adolescent adjustment was statistically significant $\left(\chi^{2}\right.$, $\mathrm{p}<.01)$ (Table 3). 
Table 3. Association between parenting style and adolescent adjustment

\begin{tabular}{|c|c|c|c|c|}
\hline \multirow[b]{2}{*}{ Parenting style } & \multicolumn{2}{|c|}{ Nature of Adolescent adjustment } & \multirow{2}{*}{$\begin{array}{l}\text { Total } \\
\mathbf{f}(\%)\end{array}$} & \multirow[b]{2}{*}{ Significance } \\
\hline & $\begin{array}{c}\text { Not well } \\
\text { adjusted } \\
\text { f }(\%)\end{array}$ & $\begin{array}{c}\text { Well adjusted } \\
\text { f (\%) }\end{array}$ & & \\
\hline Authoritative & $28(30.1)$ & $65(69.9)$ & $93(100)$ & \multirow{4}{*}{$\begin{array}{c}\chi^{2}=48.925 \\
d f=3 \\
p=.000\end{array}$} \\
\hline Authoritarian & $57(62.6)$ & $34(37.4)$ & $91(100)$ & \\
\hline Permissive/Indulgent & $37(25.7)$ & $107(74.3)$ & $144(100)$ & \\
\hline Negligent & $23(71.9)$ & $9(28.1)$ & $32(100)$ & \\
\hline
\end{tabular}

Table 4 shows stepwise multivariate logistic regression analysis performed to account for attributes of relationships, responsibilities and self as possible cofounders of association between sex and parenting style. In model 1, relationships were adjusted, whereas in model 2, responsibilities were introduced to the model. In model 3 , attributes of self were added. The adjustment of adolescent with relationships (AOR:2.0,
95\% CI:1.3-3.1), responsibilities (AOR:1.0, 95\% CI:1.0-2.6) and self-attitude (AOR:2.8, 95\% CI:1.84.4) show better among boys than girls. Regarding the adjustment of adolescent with parenting style, relationships (AOR:2.6, 95\% CI:1.1-6.0), responsibilities (AOR:4.7, 95\% CI:2.0-10.8) and selfattitude (AOR:2.7, 95\%CI:1.2-6.1), shows better adjustment with permissive parenting (Table 4).

Table 4. Logistic regression analysis of adolescent adjustment on the basis of attributes of relationships, responsibilities and self

\begin{tabular}{|c|c|c|c|c|}
\hline \multicolumn{2}{|c|}{ Attributes } & $\begin{array}{c}\text { Model 1 (AOR) } \\
\text { (Relationship) }\end{array}$ & $\begin{array}{c}\text { Model 2 (AOR) } \\
\text { (Responsibilities) }\end{array}$ & $\begin{array}{c}\text { Model 3 (AOR) } \\
\text { (Self-attitude) }\end{array}$ \\
\hline Gender & Boy & $2.0(1.3-3.1)$ & $1.6(1.0-2.6)$ & $2.8(1.8-4.4)$ \\
\hline Parenting Style & Permissive & $2.6(1.1-6.0)$ & $4.7(2.0-10.8)$ & $2.7(1.2-6.1)$ \\
\hline
\end{tabular}

Model 1: Adjusted for relationships; Model 2: Adjusted for responsibilities; Model 3: Adjusted for self.

\section{DISCUSSION}

In this study, the participants were between 15-17 years $(74.2 \%)$. The mean $( \pm \mathrm{SD})$ age of participants was $16.66 \pm 1.108$ years. In another study which was conducted at Iran (Sirjan) sample comprised among $15-18$ years old with mean $( \pm \mathrm{SD}) 15.80 \pm 1.44$ years. $^{7}$ Among 360 the participants, $(50 \%)$ were boys from Dhaka Residential Model College and (50\%) were girls from Azimpur Government Girls School and College. In another study which was done in Dhaka city comprised of total 212 participants with 130 boys and 82 girls where Male were more than female. ${ }^{8}$ Regarding education level of the students in this study, $(50 \%)$ were from secondary level and $(50 \%)$ were from higher secondary level. In a study which was done among Asian-American students in the US and Chinese students in Taiwan comprised 20,000 adolescent students from 7-12th grade in the US which over sampled Chinese-American students. ${ }^{9}$ Among participants, (95\%) were Muslim which consisted majority portion as most of the people of our country are Muslim and majority $(85.6 \%)$ were from nuclear family. Now, with the increase in urbanization, nuclear families are taking over the joint family systems. About $(56.7 \%)$ of the participants belongs to the family, with monthly family income within the range of Tk.20000-50000 as majority were from average level family income. Mean $( \pm \mathrm{SD})$ of monthly family income was Tk.58727.97 ( \pm 33215.117$)$.

Regarding parenting style on the basis of responsiveness and control, majority, (40\%) of the parents followed permissive style. In a study conducted in Dhaka showed that about $26.0 \%$ was permissive indulgent kind of parents ${ }^{5}$. In this study it was clear that, now parents mostly follows permissive style. Now 21st centuries demand with time as there 
are lots of development than earlier. During this period closeness with peer increases which tends to more important to adolescent than parents. Peer influence has both positive and negative influence. During this period, they can take decision without knowing its pros and cons. Not Thus parental supervision, control etc. increases conflicts, they don't want to share anything with parents. Moreover, adolescents are too sensitive, thus now parents are more friendly.

Adolescents relationship with staffs (teachers and others), majority, (58.6\%) of the students were not well-adjusted. Relationship with male peers and female peers, showed, $(63.3 \%)$ and $(70.0 \%)$ were well-adjusted. On the basis of responsibilities at school/work, majority, $64.7 \%$ were well-adjusted and in maintaining rules, (72.8\%) were well-adjusted. Regarding self and reality testing, majority, $(63.6 \%)$ and $(60.8 \%)$ were well-adjusted. But, $(55.0 \%)$ were not well-adjusted in impulse control. Regarding adjustment of adolescent, majority, (59.7\%) were well adjusted. A study was conducted in Bangladesh to see the relationship between students' perceptions of their teachers' and parents' (mothers' and fathers') acceptance, and teachers' reports of the students' conduct in school as well as students' reports of their own psychological adjustment. The result revealed, students perceived their parents and teachers to be fairly loving. Moreover, students reported themselves to be well adjusted, psychologically ${ }^{10}$.

The association between parenting style and adolescent adjustment was statistically significant $\left(\chi^{2}=48.925, \quad \mathrm{p}<.01\right)$. Considering the allover adjustment of adolescent, it was like to be more in permissive parenting where parents' express frequent warmth. Allow child to take their own decision, thus decision may be not suitable for them in some point but still child can adjust and develop confidence among them to adjust different situation in life. Another study was conducted among male and female adolescents on the dimensions of responsiveness and demandingness. Findings indicate that the authoritative and permissive styles (those with high levels of responsiveness) had better score than others $^{11}$.

Logistic regression of adjustment between boys and girls regarding relationships, responsibilities and selfattitude showed better adjustment of boys than girls $(\mathrm{p}<.01)$. It is obvious that, as boys are more free to roam than girl where girls are grown up conservatively. Stewart, S.M et al (2000), conducted a study in Bangladesh showed, Boys are still treated more preferentially and given greater freedom to social relationship and activities outside home with less supervision. Another, point is 'son preference' exist in various degree among most of the Bengali family ${ }^{8}$.

Similarly, logistic regression of parenting style, regarding relationships, responsibilities and selfattitude showed better adjustment in permissive parenting. Another study showed, adolescents from authoritative families evidenced the most positive levels of competence and adjustment among different variables with higher academic competence, lower levels of problem behavior, and higher levels of psychosocial development than adolescents from authoritarian families ${ }^{11}$. Another study was conducted among male and female adolescents on the dimensions of responsiveness and demandingness. Findings indicate that the authoritative and permissive styles (those with high levels of responsiveness) had better score than others ${ }^{12}$. Considering the allover adjustment of adolescents, it was like to be more in permissive parenting where parents' express frequent warmth. Allow child to take their own decision, thus decision may be not suitable for them in some point but still child can adjust and develop confidence among them to adjust different situation in life.

\section{CONCLUSION}

As a pioneering effort, the present study showed the recent picture of adjustment of adolescent and parenting style in the urban Dhaka. The study also showed different parenting styles as well as adolescent adjustments. Majority of the adolescents were well adjusted. But better adjustment was found in the boys than the girls. The study results revealed that adjustment of adolescents tends to be high in permissive parenting. The study could provide useful instructions and interventions for both parents and adolescent to ensure better adjustments. The study will also guide future comprehensive evaluation in this field.

\section{REFERENCES}

1. Baumrind, D. Current patterns of parental authority. Developmental Psychology Monograph, 1971 ;4: (1-103). http://psycnet.apa.org/record/1971-07956-001.

2. 2.Gafor A. Construction and Validation of Scale of Parenting Style. Online Submission. 2014; 2(4):315-23.

3. Hashmi S. Adolescence: An age of storm and stress. Review of Arts and Humanities. 2013 Jun;2(1). 
4. Chauhan, U., Golhar, S. and Madhura, A. Effects of different parenting styles on adolescent adjustment. Int J Res Med, 2016;5(2):6-11.

5. Kabir, R. and Sultana, M.Z. Adolescents' and their Mothers: Understanding the Needs, International Journal of Indian Psychology, 2017; 4 (3), ISSN:2348-5396 (e), ISSN: 23493429 (p), DIP: 18.01.007/20170403.

6. Steinberg L, Morris AS. Adolescent development. Annual review of psychology. $2001 \mathrm{Feb} ; 52(1): 83-110$.

7. 7.Dehyadegary E, Yaacob SN, Juhari RB, Talib MA. Relationship between parenting style and academic achievement among Iranian adolescents in Sirjan. Asian Social Science. 2012 Jan 1;8(1):156.

8. Stewart SM, Bond MH, Abdullah AS, Ma SS. Gender, parenting, and adolescent functioning in Bangladesh. Merrill-Palmer Quarterly (1982-). 2000 Jul 1:540-64.

9. Pong SL, Johnston J, Chen V. Authoritarian parenting and Asian adolescent school performance: Insights from the US and Taiwan. International journal of behavioral development. 2010 Jan;34(1):62-72.

10. Rohner RP, Khaleque A, Shamsuddin Elias M, Sultana S. The relationship between perceived teacher and parental acceptance, school conduct, and the psychological adjustment of Bangladeshi adolescents. Cross-Cultural Research. 2010 Aug;44(3):239-52.

11. Lamborn SD, Mounts NS, Steinberg L, Dornbusch SM. Patterns of competence and adjustment among adolescents from authoritative, authoritarian, indulgent, and neglectful families. Child development. 1991 Oct;62(5):1049-65.

12. 12. Boer OE, Tranent PJ. Conceptualising the relationship between maternal parenting style and adolescent self-esteem: A pragmatic approach. Journal of Relationships Research. $2013 ; 4$. 